\title{
Mental health aspects of incapacity benefit
}

\author{
Laurence G. Measey
}

In February 1994 the Royal College of Psychiatrists contacted the Benefits Agency Medical Services (BAMS) to take part in their consultation exercise before bringing in the new Incapacity Benefit (IB) in April 1995. This new benefit was to replace the then existing Invalidity Benefit which was being paid to over 250000 people with a primary diagnosis of mental illness. The main changes were that a patient's own general practitioner (GP) would certify incapacity for work for the first 29 weeks of sickness and after this the continuation of benefit (IB) would require assessment by a BAMS doctor, with some illness categories being exempt from medical examination. The aim was to create standardised criteria across the UK and to do so in an objective fashion, based on function rather than diagnosis. The test is designed to look at ability to work in any capacity rather than the claimant's own work which is the criterion for the first 29 weeks.

The College has been concerned that although mental illness was recognised as needing special care in its assessment, the initial proposals of BAMS seemed unsatisfactory. The proposals included a mental health questionnaire and examination of cases that did not satisfy the tough criteria for severe mental illness. A meeting was convened between BAMS and the President and the Registrar of the College to discuss these issues further. At this meeting it was clear that the BAMS policy division had undertaken a major review of the process for mentally ill persons making a claim under the new system and that they were anxious to receive additional assistance in making the process both fair and accurate. The process was modified as described below.

\section{The process}

All persons with severe mental illness should be exempt from the 'all work test'. Such an exemption would be given by a BAMS doctor upon scrutiny of a questionnaire completed by the patient's own doctor with additional information from the treating psychiatrist if there was a need to clarify matters further.

The mental health questionnaire which was to be completed by the claimant was scrapped as this was seen as difficult to validate and creating more paperwork which might confuse rather than clarify issues.

The mental health incapacity examination would be needed for those with physical and sensory deficits in whom there was a significant degree of psychological disability. Also, in order that the converse was not overlooked, all those who were not judged to have a mental illness would be asked to fill in the physical and sensory questionnaire before attending examination. A system of scoring was designed so that persons with multiple incapacities would have their scores weighted and summed.

The appeals process would be applied to all those who were found fit for work but felt that they had been unfairly treated.

During further meetings it was resolved that members of the College should undertake the process of training the BAMS doctors in the interpretation of the definition of severe mental illness along the lines that were agreed and also give training in the conduct of the mental health examination. A total of 16 courses were taught with approximately $\mathbf{5 0 0}$ doctors attending.

\section{Definition of severe mental illness}

Severe mental illness, for the purpose of the test, was defined not by diagnosis but rather by the resulting dysfunction. This dysfunction could affect mood, behaviour, social and environmental awareness including interpersonal relationships so as to require continuous psychiatric care. Care would include sheltered residential facilities where a person would recetve regular nursing or medical supervision, or attendance at a day centre for ongoing treatment or care for at least one day per week, and/or long-term treatment with antipsychotic medication including depot neuroleptics.

The initial screen, in the case of mental illness, is carried out by the claimant's own doctor who is asked to fill in a short report detailing the care and medication which the patient is receiving. The GP would also have the opportunity to make additional comments in a free text box and give details of the consultant psychiatrist who had seen the patient within the previous three 
months. As it is the BAMS doctors who would issue an exemption certificate from further examination, the following guidelines were made to assist them with this task.

\section{Conduct of mental health eramination for BAMS doctors}

\section{Care}

Care is now commonly deltvered in the community in sheltered settings which have employed care staff, but frequently persons with severe mental illness are cared for in their homes by a relative. In the case of home care the relative often has access to help from a community support team and to respite care in residential placements.

Day care can be in a variety of settings: day hospitals, rehabilitation day units, day centres and drop-in centres. To meet the criteria within the severe mental illness definition the patient should be attending a centre where there are at least visiting professional mental health workers.

\section{Medication}

Severe mental illness usually requires continuous, and frequently long-term medication. It is not unusual for patients to be in receipt of combination therapy which can indicate the complexity of their illness. Anticonvulsant medication is sometimes used as a mood stabiliser with or without lithium carbonate.

Antidepressants and minor tranquillisers are frequently prescribed and do not in themselves indicate a severe mental illness. The additional care factors will need to be scrutinised to determine if the criteria are met, or an assessment examination may be necessary.

\section{Other discriminators}

The free text box in the initial enquiry form sent to the GP when mental illness appeared to be the main ground for disability may add considerably to the understanding of a case. This might include family factors such as the burden of care, ongoing stress factors which perpetuate the disability, and history of hospital admissions.

A report from the consultant psychiatrist who has been involved with the patient should be requested if the patient has been in hospital within the previous three months, or when there are specific issues that need to be clarified. It is important to be specific when requesting such a report and to ask the questions which are necessary to resolve difficulties.

\section{The assessment interview}

The mental health interview may easily take up the 45 minutes that are allowed for the completion of the 25 descriptors in the schedule. Each of the descriptors will need to be assessed, and comments as well as scores entered on the questionnaire. However, a mechanical approach to the interview by plodding through the descriptors is not only bad technique but can produce false positives or negattve responses.

An emphatic approach is important as claimants may arrive for the examination anticipating a confrontational interview and appear very wary. Persons with a mental illness are no more deceitful than the rest of the population but may have difficulties in expressing themselves. A helpful attitude is most likely to produce accurate results.

Open rather than direct questions are always to be preferred as they allow persons to describe their problems in the order that seems important to them. This technique is, of course, not just confined to psychiatric practice, it is also an established method for all medical enquiries. However, it is crucial when dealing with psychiatric phenomena.

The assessor should enquire how an average day is spent. From the general enquiry stem more specific information can be gathered in order to complete the descriptors. Similarly, it is better to ask 'how' questions rather than why' and to flesh out the answer with supplementaries such as "could you give me an example of that?"

\section{Some special problems}

Language Persons for whom English is not their mother tongue may not always be able to be intervlewed in that language. Certain languages have few words to describe emotional conditions, for example, there are no equivalent words in some of the Northern Indian languages to describe depression. In these circumstances metaphors are used such as a 'sinking feeling' or 'heart is troubled'. Problems with energy, interest and concentration may be described as tiredness or malfunction of a part of the body, for example, "my eyes won't read properly".

Culture Among some peoples there is a desire to demonstrate that they are 'good' and therefore worthy of receiving benefits. Such persons may well minimise difficulties leading to a false impression of their incapacity. This is apparent if the first reply to open questions does not elicit any difficulty. In such cases it is important to quiz details pertinent to that question before moving on to another area. 
Somatisation This can cause considerable problems and has a variety of causes. As indicated above, language may not be sufficient to describe emotional experiences but this is also true for people who are unsophisticated in the use of psychological language. Older people in particular tend to use physical explanations or expressions such as 'mithered' or 'mardy' which do not translate effectively as muddled or out of touch but are generic expressions of mental agitation or dysfunction.

Depresstve illness and some paranoid disorders may also present with predominately somatic symptoms and indeed may be the cause of unnecessary physical investigations before the true cause of the disability is elucidated. Medical assessors will need to be aware of this as some persons called for physical examination may require further mental assessment.

\section{Validation}

The Social Security (Incapacity for Work) General Regulations 1994 made it clear that a doctor carrying out the Incapacity Benefit medical assessment, or issuing a certificate of exemption from the all work test would have to be approved by the Secretary of State for Social Security. The responsible minister formed a validation group whose brief is to:

- Validate the criteria for the approval process for all BAMS doctors who will be applying the all work test and related medical problems.

- Oversee the approval process, ensure that it proceeds on time and that any problems are reported to and resolved by line management.

- Validate the criteria and processes for the continued monitoring of the performance of BAMS doctors in IB.
- Report on standards of performance achieved by BAMS doctors.

- Report to the Department any information which may be relevant to the monitoring and evaluation of the all work test or related medical procedures.

The validation group has three medical members who are not part of the Department's staff, consisting of an expert in medical incapacity, a professor of rheumatology, and a consultant rehabilitation psychiatrist. This will allow for additional input of psychiatric advice as the test proceeds and may mean that alterations can be made to the test if there is clear evidence of problems which need rectifying in the interests of both the efficiency of the test as well as its fairness.

\section{Conclusion}

The introduction of the new Incapacity Benefit posed a number of potential problems for persons with mental health problems. The College has made full use of the request for help and assistance with the development of the test and has vigorously represented the welfare interests of its patient group. Some success has been achieved in modifying the regulations and the process, with a particular emphasis on the training of those doctors who will be certifying exemptions to the test and carrying it out. The ongoing involvement with the validating group offers additional opportunities to monitor the benefit in action which can allow for operational alterations to be made.

Laurence G. Measey, Nine Hills Cottage, Offchurch, Leamington Spa, Warwickshire CV33 9AQ 